\title{
The Effect of Pre-treatment Intraretinal Cyst Diameter on Visual and Anatomical Outcomes after Intravitreal Ranibizumab Treatment in Cystoid Macular Edema Secondary to Branch Retinal Vein Occlusion
}

\author{
(D) Alper Halil Bayat, (D) Akın Çakır, (D) Selim Bölükbaşı, (D) Burak Erden, (D) Şeyma Gülcenur Şehirli, (D) Mustafa Nuri Elçioğlu \\ University of Health Sciences, İstanbul Okmeydanı Training and Research Hospital, Department of Ophthalmology, Istanbul, Turkey
}

\section{Abstract}

Objective: To investigate the effect of the largest intraretinal cyst diameter in the macula on visual and anatomical outcomes after intravitreal ranibizumab (IVR) treatment in cystoid macular edema (CME) secondary to branch retinal vein occlusion (BRVO).

Methods: Forty-two eyes of 42 patients who underwent IVR treatment for CME secondary to BRVO were studied retrospectively. Patients were evaluated after three-monthly IVR injection. The pre-treatment and post-treatment spectral domain optical coherence tomography parameters and best-corrected visual acuity (BCVA) were recorded. The effect of pre-treatment intraretinal cyst diameter on post-treatment central macular thickness (CMT) and BCVA was investigated.

Results: There were 27 (64.3\%) men and 15 (35.7\%) women in the study. The mean age was 59.5 \pm 9.6 years. The mean pre-treatment CMT was $485 \pm 160 \mu \mathrm{m}$ and the mean pre-treatment BCVA was $0.84 \pm 0.55 \log$ MAR. After 3 doses of IVR, CMT gain was $201 \pm 168 \mu \mathrm{m}$ and BCVA gain was $0.41 \pm 0.43$ $\log$ MAR. The mean pre-treatment cyst diameter was $241 \pm 121 \mu \mathrm{m}$. Although there was a low degree positive correlation between pre-treatment cyst diameter and CMT gain, this correlation was not statistically significant $(r=0.245, p=0.059)$. Although there was a low degree negative correlation between pre-treatment cyst diameter and BCVA, this correlation was not statistically significant $(r=-0.145, p=0.184)$.

Conclusion: There was no statistically significant correlation between pre-treatment cyst diameter and CMT and BCVA gain in CME treatment secondary to BRVO.

Keywords: Branch retinal vein occlusion, intraretinal cyst diameter, macular edema, optical coherence tomography

\section{INTRODUCTION}

Retinal vein occlusion is the most common retinal vascular pathology after diabetic retinopathy (1). Retinal vein occlusions are divided into two as central retinal vein occlusions and branch retinal vein occlusions (BRVOs). Vascular pressure during the arteriovenous transition, degenerative changes in veins and hypercoagulability are the major pathophysiological events that cause BRVO. These events increase vascular endothelial growth factor (VEGF) secretion and increase vascular permeability and thus cause macular edema $(2,3)$. Macular edema is the most common cause of visual loss in BRVO $(4,5)$. Laser photocoagulation, intravitreal steroid injection and intravitreal anti-VEGF injection are used for the treatment of macular edema $(6,7)$. The same results cannot be obtained from all patients despite anti-VEGF therapy. This may be due to the fact that the pathophysiology of the disease cannot be fully elucidated or it may be due to the pre-treatment factors related to the patient.

Cite this article as: Bayat AH, Çakır A, Bölükbașı S, Erden B, Şehirli ȘG, Elçioğlu MN. The Effect of Pre-treatment Intraretinal Cyst Diameter on Visual and Anatomical Outcomes after Intravitreal Ranibizumab Treatment in Cystoid Macular Edema Secondary to Branch Retinal Vein Occlusion. Eur Arch Med Res 2019;35 (1):11-14

๑Copyright 2019 by the Health Sciences University, Okmeydanı Training and Research Hospital European Archives of Medical Research published by Galenos Publishing House. 
The aim of this study was to investigate the effect of pretreatment cyst diameter on visual and anatomic outcome in cystoid macular edema (CME) secondary to BRVO.

\section{METHODS}

The data of 42 patients, who were admitted to Okmeydanı Training and Research Hospital Retina Outpatient Clinic between January 2015 and January 2017 and who were treated with intravitreal ranibizumab (IVR), were evaluated retrospectively. The study was conducted in accordance with the Declaration of Helsinki and the ethics committee approval was obtained from the Ethics Committee of Okmeydanı Training and Research Hospital.

All of the patients received three-monthly IVR treatment. Patients with cystic changes due to intraretinal fluid accumulation in any retinal layer detected by spectral domain optical coherence tomography (SD-OCT) were included in the study with the diagnosis of CME (Figure 1).

Data regarding age, gender, pre-treatment and post-treatment best-corrected visual acuity (BCVA) and central macular thickness (CMT) were recorded. Pre-treatment CMT and intraretinal foveal cyst diameters obtained from SD-OCT images were noted. Cyst diameters were measured as the vertical diameter of the largest intraretinal cyst in the SD-OCT sections by two different ophthalmologists. The cyst diameter was measured manually using the caliper in the device (Figure 2). The mean values of these measurements were accepted as data. There were no statistically significant differences between the measurements of two ophthalmologists.

All patients underwent routine ophthalmologic examination before the treatment and at the first month after three-

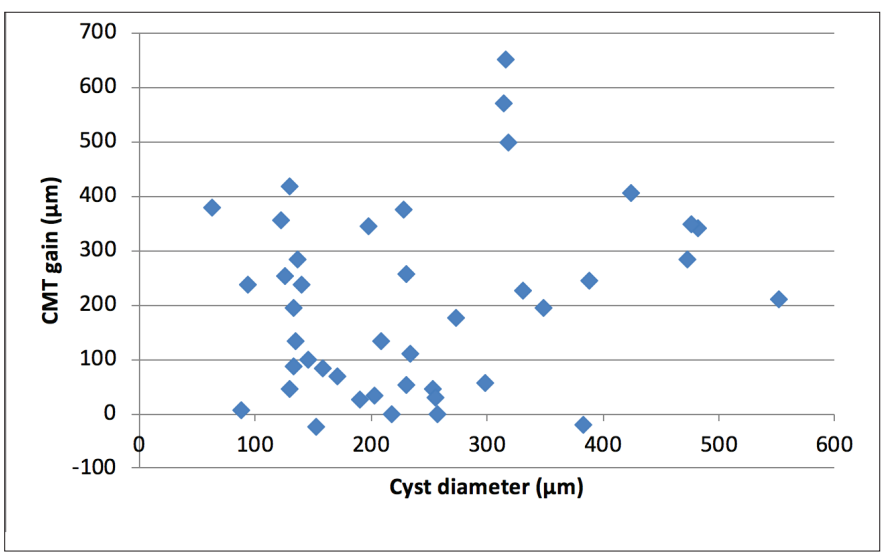

Figure 1. The relationship between pre-treatment cyst diameter and CMT gain (scatter-plot) shows no significant trend in distribution CMT: Central macular thickness monthly treatment. Biomicroscopic examination, indirect ophthalmoscopy, BCVA measurement, intraocular pressure measurement with Goldmann applanation tonometry, and SD-OCT (Heidelberg engineering, Heidelberg, Germany) were performed respectively. Best-corrected visual acuity was determined with Snellen chart and converted to "the logarithm of the minimal angle of resolution (logMAR)" unit for statistical analysis.

Patients with glaucoma, other macular and/or retinal disease, neurological and systemic diseases that cause vision loss and patients who did not received three-monthly IVR treatment were not included in the study.

\section{Statistical Analysis}

Data were analyzed using SPSS for Windows 21 software (IBM Corp., Armonk, NY, USA). Descriptive statistics were shown as mean \pm standard deviation (smallest-largest) for continuous variables and categorical variables as number of cases and percentage (\%). A multivariate linear regression analysis was performed to examine the effect of pre-treatment findings on BCVA and CMT gains. Significance was evaluated at $p<0.05$. After the study, post-hoc power analysis was performed with $\mathrm{G}^{*}$ Power 3.1 (Heinrich-Heine-Universität, Düsseldorf, Germany) and the power of the study was $99.9 \%$.

\section{RESULTS}

Forty-two eyes of 42 patients diagnosed as having CME secondary to BRVO were included in this study. Of these patients, 27 were male (64.3\%) and 15 were female (35.7\%). The mean age was $59.5 \pm 9.6$ years. The mean follow-up period was $5.7 \pm 0.7$ months. The mean CMT was $485 \pm 160 \mu \mathrm{m}$. The pre-treatment BCVA was calculated as $0.84 \pm 0.55 \log M A R$. After 3 doses of IVR, CMT and BCVA gains were $201 \pm 168 \mu \mathrm{m}$ and $0.41 \pm 0.43$

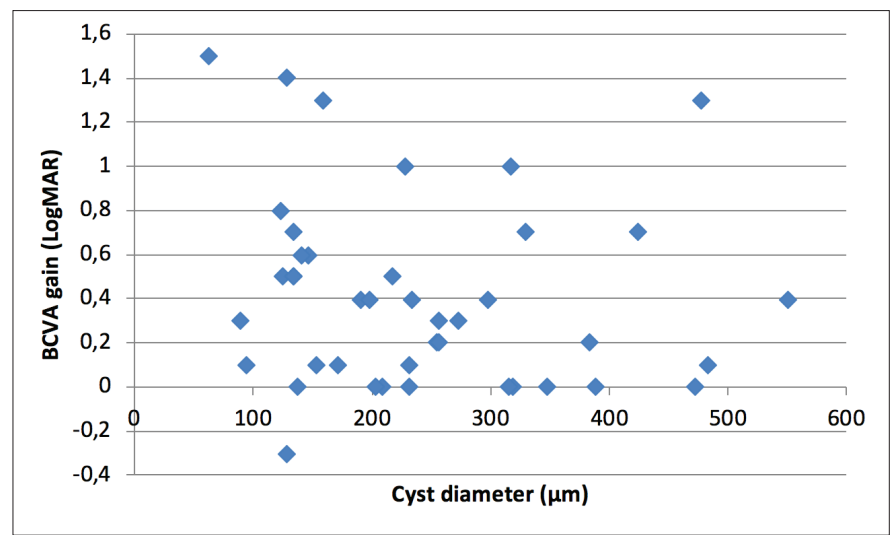

Figure 2. The relationship between pre-treatment cyst diameter and BCVA gain (scatter-plot) shows no significant trend in distribution BCVA: Best-corrected visual acuity 
$\log \mathrm{MAR}$, respectively. The mean pre-treatment cyst diameter was $241 \pm 121 \mu \mathrm{m}$.

Multivariate linear regression analysis was performed by using the "Backward" method to compare the factors that could have a prognostic and predictive effect on the BCVA and CMT gains. The relationships between age, gender, pre-treatment cyst diameter, BCVA and CMT and BCVA and CMT gains were investigated.

The CMT gain was statistically significantly correlated with pretreatment CMT and BCVA values $(r=0.879$ and $p<0.001, r=0.589$ and $p<0.001$, respectively) (Table 1). Although there was a positive correlation between the pre-treatment cyst diameter and CMT gain, this correlation was not statistically significant $(r=0.245, p=0.059)$ (Table 1). The relationship between pretreatment cyst diameter and CMT gain is shown in Figure 1. As can be seen, there is no trend in this distribution (Figure 1). Pretreatment BCVA and CMT values were significantly related with BCVA gain ( $r=0.440, p=0.002$ and $r=0.340, p=0.014$, respectively) (Table 1). Although there was a negative correlation between pre-treatment cyst diameter and BCVA gain, this correlation was not statistically significant $(r=-0.145, p=0.180)$ (Table 1). This relationship is shown in figure 2 and no trend was observed in this distribution.

\section{DISCUSSION}

In recent literature, there are many studies that have demonstrated the efficacy of ranibizumab in the treatment of CME due to BRVO (8-12). But as seen in these studies, all patients do not give the same response to this treatment. This suggests that there are other factors affecting the success of the treatment, as well as the pathophysiological process of the disease, which is not fully elucidated. There are some publications investigating this situation in the current literature $(13,14)$.

According to the results of this study, patients with high pretreatment CMTs had higher CMT gains. In their study, Ach T et al. (15) also found that pre-treatment CMT was a good prognostic factor in response to anti-VEGF treatment. In this study, it was

Table 1. Regression coefficients and $p$ values of parameters affecting CMT and BCVA gains

\begin{tabular}{|l|l|l|l|l|}
\hline & \multicolumn{2}{|l|}{ CMT gain } & \multicolumn{2}{l|}{ BCVA gain } \\
\hline & $\begin{array}{l}\text { Beta } \\
\text { coefficient }\end{array}$ & $\mathbf{p}$ & $\begin{array}{l}\text { Beta } \\
\text { coefficient }\end{array}$ & $\mathbf{p}$ \\
\hline $\begin{array}{l}\text { Pre-treatment cyst } \\
\text { diameter }\end{array}$ & 0.245 & 0.059 & 0.145 & 0.180 \\
\hline Pre-treatment CMT & 0.879 & $<\mathbf{0 . 0 0 1}$ & 0.340 & $\mathbf{0 . 0 1 4}$ \\
\hline Pre-treatment BCVA & 0.589 & $<\mathbf{0 . 0 0 1}$ & 0.440 & $\mathbf{0 . 0 0 2}$ \\
\hline CMT: Central macular thickness, BCVA: Best-corrected visual acuity \\
\hline
\end{tabular}

also found that the patients with low BCVA had more CMT gain. The fact that patients with increased pre-treatment CMT had low pre-treatment BCVA would explain this situation. Indeed, Kriechbaum et al. (16) support this finding.

Some previous studies have shown that patients with low pretreatment BCVA have lower post-treatment BCVA (17). In contrast, patients with lower pre-treatment BCVA were found to have higher visual gain in this study. The study by Gesine B. Jaissle et al. (13) supports this finding. This can be explained by the "ceiling effect" in the literature. "Ceiling effect" is the situation that explains that patients with lower pre-treatment values will have more gain as a result of reaching the maximum value.

In their study, Groneberg T et al. (18) found that the pre-treatment cyst diameter was associated with visual gain. They showed that small cysts had more letter gain. In contrast to Groneberg T et al. (18), we could not find a statistically significant relationship between pre-treatment cyst diameter and BCVA and CMT gains in this study.

\section{CONCLUSION}

In conclusion, pre-treatment BCVA and CMT can be used as a prognostic factor for visual gain and anatomic success in the treatment of CME secondary to BRVO. In contrast, we believe that the use of pre-treatment cyst diameter as a prognostic factor is not appropriate.

\section{Ethics}

Ethics Committee Approval: Retrospective study.

Informed Consent: Retrospective study.

Peer-review: Externally peer-reviewed.

\section{Authorship Contributions}

Surgical and Medical Practices: A.H.B., A.Ç., S.B., B.E., S.C.S., M.N.E., Concept: A.H.B., Design: B.E., M.N.E., Data Collection or Processing: A.H.B., A.Ç., S..C.S.., Analysis or Interpretation: A.Ç., Literature Search: A.H.B., S.B., Writing: A.H.B.

Conflict of Interest: No conflict of interest was declared by the authors.

Financial Disclosure: The authors declared that this study received no financial support.

\section{REFERENCES}

1. Rogers S, McIntosh RL, Cheung N, Lim L, Wang JJ, Mitchell P, et al. The Prevalence of Retinal Vein Occlusion: Pooled Data from Population Studies from the United States, Europe, Asia, and Australia. Ophthalmology 2010;117:313-9. 
2. Jaulim A, Ahmed B, Chatziralli IP. Branch Retinal Vein Occlusion: Epidemiology, Pathogenesis, Risk Factors, Clinical Features, Diagnosis, And Complications. An Update Of The Literature. Retina 2013;33:901-10.

3. Son BK, Kwak HW, Kim ES, Yu SY. Comparison of Ranibizumab and Bevacizumab for Macular Edema Associated with Branch Retinal Vein Occlusion. Korean J Ophthalmol 2017;31:209-216.

4. Cruz N, Pinilla I, Casas P. et al. Ranibizumab for Macular Edema Following Branch Retinal Vein Occlusion. Acta Ophthalmologica 2010;88.0.

5. Moon BG, Cho AR, Kim YN, Kim JG. Predictors Of Refractory Macular Edema After Branch Retinal Vein Occlusion Following Intravitreal Bevacizumab. Retina 2017;0:1-9.

6. Mylonas G, Sacu S, Dunavoelgyi R. Response Of Retinal Sensivity To Ranibizumab Treatment Of Macular Edema After Acute Branch Retinal Vein Occlusion. Retina 2013;33.6:1220-6.

7. Korobelnik JF, Kodjikian L, Delcourt C, Gualino V7, Leaback R, Pinchinat S, et al. Two-Year, Prospective, Multicenter Study of The Use Of Dexamethasone Intravitreal Implant For Treatment Of Macular Edema Secondary To Retinal Vein Occlusion In The Clinical Setting In France. Graefes Arch Clin Exp Ophthalmol 2016;254:2307-18.

8. Campochiaro PA, Heier JS, Feiner L, Gray S, Saroj N, Rundle AC, et al. Ranibizumab For Macular Edema Following Branch Retinal Vein Occlusion: Six-Month Primary End Point Results Of A Phase III Study. Ophthalmology 2010;117:1102-12.

9. Brown DM, Campochiaro PA, Bhisitkul RB, Ho AC, Gray S, Saroj N, et al. Sustained Benefits From Ranibizumab For Macular Edema Following Branch Retinal Vein Occlusion: 12-Month Outcomes Of A Phase III Study. Ophthalmology 2011;118:1594-602.

10. Minami $Y$, Nagaoka T, Ishibazawa A, Yoshida A. Short-Term Effect Of Intravitreal Ranibizumab Therapy On Macular Edema After Branch Retinal Vein Occlusion. Retina 2016;36:1726-32.
11. Sophie R, Hafiz G, Scott AW, Zimmer-Galler I, Nguyen QD, Ying H, et al. Long-Term Outcomes In Ranibizumab-Treated Patients With Retinal Vein Occlusion; The Role of Progression of Retinal Nonperfusion. Am J Ophthalmol 2013;156:693-705.

12. Brynskov $\mathrm{T}$, Kemp H, Sorensen TL. Intravitreal Ranibizumab For Retinal Vein Occlusion Through 1 Year In Clinical Practice. Retina 2014;34:1637-43.

13. Jaissle GB, Szurman P, Feltgen N, Spitzer B, Pielen A, Rehak M, et al. Predictive Factors For Functional İmprovement After İntravitreal Bevacizumab Therapy For Macular Edema Due To Branch Retinal Vein Occlusion. Graefes Arch Clin Exp Ophthalmol 2011;249:183-92.

14. Mo B, Zhou HY, Jiao X, Zhang F. Evaluation Of Hyperreflective Foci As A Prognostic Factor Of Visual Outcome In Retinal Vein Occlusion. Int J Ophthalmol 2017;10:605-12.

15. Ach T, Hoeh AE, Schaal KB, Scheuerle AF, Dithmar S. Predictive Factors For Changes In Macular Edema In Intravitreal Bevacizumab Therapy Of Retinal Vein Occlusion. Graefes Arch Clin Exp Ophthalmol 2010;248:155-9.

16. Kriechbaum K, Michels S, Prager F, Georgopoulos M, Funk M, Geitzenauer W, et al. Intravitreal Avastin For Macular Oedema Secondary To Retinal Vein Occlusion: A Prospective Study. Br J Ophthalmol 2008;92:518-22.

17. Kondo M, Kondo N, Ito Y, Kachi S, Kikuchi M, Yasuma TR, et al. Intravitreal Injection Of Bevacizumab For Macular Edema Secondary To Branch Retinal Vein Occlusion: Results After 12 Months And Multiple Regression Analysis. Retina 2009;29:1242-8.

18. Groneberg T, Trattnig JS, Feucht N, Lohmann CP, Maier M . Morphologic Patterns on Spectral-Domain Optical Coherence Tomography (SD-OCT) as a Prognostic Indicator in Treatment of Macular Edema Due to Retinal Vein Occlusion. Klin Monbl Augenheilkd 2016;233:1056-62. 